Interfaces

\section{Free enterprise - The reluctant supporters - S.A. Institutions}

\author{
P.M. Collins \\ Chairman, Collins Corporation (Pty) Ltd., \\ P.O. Box 781979, Sandion 2146, South Africa
}

An address to the Institute of Directors Seminar at Cape Town on 12 March 1981

My theme today is the reluctant supporters of free enterprise - the South African Institutions. In the limited time available in a speech of this nature it is not possible for me to go into any great depth on a variety of aspects of this theme. If you will bear with me I intend taking you on a short tour of The United States, Europe and then homing in on our South African situation.

\section{Objectlve}

My objective in this speech is to sow seeds of thought around the financial aspect of free enterprise and the development of sources of finance for businesses. Of necessity I will demonstrate to you that the small business is the vibrant force in a free enterprise economy and I have tended to concentrate more on the role of small business and its sources of finance, rather than being involved in the machinations of the institutional corporations. I use the word institutional here because I believe that the larger the firm becomes, the more institutionalized and bureaucratic it tends to become.

\section{Hypothesis}

My main hypothesis to you is that if venture capital is supplied to small businesses and it is controlled successfully, we will produce in South Africa a vibrant economy, a high standard of living for all citizens and a great deal of job satisfaction for a vast majority of the population. I also believe that through this can be created a level of political stability. However, I do not think that the fostering of private enterprise on its own through the financing of the entrepreneur can solve social problems. We in Southern Africa must not think that this is the case. Certainly business and society abroad have realized that private enterprise does not necessarily solve social problems. It means that we must bear in mind the emphasis on what business should be doing and can do, that is, producing goods and services for a profit.

\section{U.S.A.}

Small business has always played an important role in the American economy. This is still true in this last quarter of the 20th Century. Furthermore, although it is not generally recognized, this segment of the American economy includes some of the most dynamic, profitable and interesting firms to be found.

There are a number of reasons why smaller firms are of importance to the American economy and I believe these will also become increasingly important to the Southern African economy. These are:

- Small businesses are an important source of competition and challenge to the economic power of larger firms.

- They offer a wide range of choice to the consumer. Larger firms must be oriented towards the mass market. Smaller firms can serve specialized needs.

- Small firms broaden the distribution of economic and political power. In many areas small business provides local leaders with strong local roots.

- Small firms are sources of innovation and creativity. Many innovations in services and technology have originated in small firms.

- Small firms offer career opportunities to those who are happiest and most productive in the unstructured environment of a small company.

Small firms are not only of value to those who are attracted to careers in small organizations. Many other individuals will move into career positions in which they will deal with and must understand the special characteristics of small companies. Bankers, purchasing agents, salesmen, investment analysts, venture capitalists and consultants are examples.

Managers in large firms that compete with small companies can also benefit from a better understanding of their adversaries. Finally, particularly in the study of management through cases, there is much to be said for analyzing problems within the context of a small company. It is easier 'to get your arms around the situation' and to understand the inter-relationships in a small company, than in a large one.

\section{Small business statistics - U.S.A.}

Small business is often considered to be companies that have fewer than 100 employees, and are characterized by small cohesive management groups in direct contact with customers, with workers, and with day to day problems.

The higher visibility of giant American corporations means that many people do not realize that most American firms are small. To quote from Hosmer/ Cooper/Vesper in their book 'The Entrepreneurial Function', let us consider some of the following statistics:

- Of over 12 million businesses in America, only $13,9 \%$ are corporations, the rest are organized as proprietorships or partnerships and tend to be small.

- Of the active corporations, $57,7 \%$ have less than 100000 U.S. Dollars in assets, and $93,7 \%$ have less than 1 million dollars in assets.

- Approximately $95 \%$ of all businesses have fewer than 20 employees. These account for approximately $23 \%$ of all employment by industry.

By all measures, small business constitutes an important part of the American economy.

The population of small firms is highly dynamic. 
Overall figures conceal a great deal of churning as companies start and discontinue. The importance of small business varies widely across industries. Furthermore in some industries small firms are enlarging their market share, but in others the tides of competition are favouring the large companies.

- In 1972, 317000 new corporations were established. In a typical 40 hour week, approximately 158 new corporations were established per hour and almost as many were discontinued. (In South Africa we have anything from 5000 to 7000 new companies formed during a year).

- Approximately two out of every three new businesses discontinue in the first four years after founding. As a business gets older the probability that it will survive each additional year increases.

- Some industries, for example primary aluminium, automobiles and cigarettes are highly concentrated with small firms playing a minor role, except as suppliers and distributors. Other industries, for example furniture, apparel and printing and publishing are highly fragmented with many small companies.

- Brewing, bread, photographic equipment and suppliers are examples of industries in which large companies have been expanding their market shares. In meat packing, plastic materials, resins and knitted fabrics the contrary is true, for these industries are becoming less concentrated.

Available profitability data suggest that when averaging all manufacturing firms within a given size class, profitability increases with size of firm. Within each of these size categories, however, there are wide differences in profitability. Smaller size categories in particular include well established profitable firms, new companies showing what is often an expected loss in their first year and unfortunately thousands of companies that should never have been started. In the large firm categories there is also dispersion but much less, as the performance of these large companies reflects the averaging of many products, many facilities and many people. Some of these resources are outstanding, but some are not. The result is that the performance of the larger firms as a group is stabilized and brought towards the middle.

The image of small businesses in the U.S.A. is highly influenced by the many marginal small companies. Many of these firms - ill-conceived, ill-financed and illmanaged - are doomed to failure before they ever start. In every town there are retail locations that need revolving doors not for the few customers but for the stream of entrepreneurs that come and go. Nevertheless the dismal performance of these marginal companies should not obscure the presence of another class of small firms. These well planned and excellently managed businesses are as a group showing some of the highest returns to be found in the American industry. They are demonstrating what can be done in small business.

With this backdrop as an introduction, many of you might be asking why should we be considering the role of small business when it appears that it has a high failure rate. Using medicine as an example, not so many years ago, the infant mortality rate was exceptionally high and in certain undeveloped countries today, this infant mortality rate is still high. However, with the introduction of advanced medicine the infant mortality rate has been greatly reduced. With advanced management techniques the small business mortality rate can reduce.

As I have already indicated above, small business includes a variety of companies, and encompasses a wide range of performance. One way of classifying these firms is as follows:

- 'Mom and Pop' companies - family businesses.

- Stable high pay-off companies.

- Rapid growth companies.

The strategies, available resources and potential rewards vary widely among these types of firms. They also differ greatly in the kinds of careers they make possible.

\section{Venture capital U.S.A.}

For most small companies personal savings, trade credit and bank loans are the main sources of capital. Companies that grow rapidly, however, may need more capital than these sources plus earnings can provide. Such additional need of money is often referred to as venture capital and may be obtainable from a number of sources including the following:

- Wealthy individual backers.

- Venture capital companies.

- Private stock offering.

- Registered stock offering.

- Other companies and approaches.

The aspect that $I$ am going to concentrate on is to deal with the possibility of venture capital companies. I will later deal with a definition of venture capital which has in fact varied and evolved over the last few years with differing interpretations being placed varying from that of a bureaucratic approach to almost a gambling approach. In fact I believe one can draw a graph with the degree of profitability as a function of bureaucracy towards individualism. This means taking the government view across to a gambler's view. The risk element in venture capital tends towards the gambling side of the graph but likewise has, because of its high risk, the higher profit elements.

\section{Venture capital companies - U.S.A.}

Generally, there are two types of companies formed for the purpose of providing venture capital. The first are private venture capital companies that invest in ventures according to their own rules. The second are the Small Business Investment Companies (S.B.I.C.'s) that agree to operate according to investment rules set forth by the Small Business Administration of the U.S. Department of Commerce, in return for being able to borrow investment money from that agency under favourable terms designed to encourage these investments. From the small company manager's point of view, however, these two types of investment companies are essentially the same.

Because the ventures they invest in tend to be risky, (possibly only one investment out of ten turning out to be highly profitable, with a large fraction failing entirely 
and the rest doing only moderately well), these venture capital firms have to seek a high return: a rule of thumb for many being the aim of multiplying the investment from threefold to fivefold within five years. These firms will want to be able to have stock (shares) - for their money - at some point. Often they invest through convertible debentures, bonds that can be converted into stock (shares), according to some fixed formula over a stated period of time. Sometimes they base the formula upon the company's forecast - thus the better the company does, the smaller the fraction of stock they can take through conversion, and vice versa. Often they will require a seat on the board of directors and they may impose other constraints, for example interest charges, consulting retainer fees, maintenance of certain performance limits by the company and so forth.

Before investing in a small company, a venture capital firm will usually undertake an extensive investigation of the company, its industry and the prospects of the company's future. Because the investigation costs time and money and because many proposals are typically screened for each one accepted (roughly 30 out of 100 may receive serious attention, and fewer than five will be accepted), the venture capital firm must confine its attention to companies in which the investment and potential pay-off are large in absolute dollar amounts. Investments of less than 150000 dollars are usually regarded as too small to warrant serious attention and investigation. However, the investment may be staged in increments according to the new companies' progress and needs so that the initial investment by the venture capital firm may be small with larger amounts being added later. Typically the venture capital firm will want to see a pay back within five years to be seriously interested in a proposition.

As in dealing with private investors, small companies should select venture capital firms carefully. Some firms have more experience than others and can be of more help to the company. Others have reputations for bleeding the companies they invest in by extracting high interest or consulting fees or for meddling unhelpfully in management. A particularly important point in the relationship with a venture capital firm can be the time in which the small company must return for a second round of financing. Experienced venture capitalists are better able to anticipate and be helpful when such needs arise, but less experienced investors have been known to panic or get tough in these circumstances. Reputable venture capitalists usually realize that they will fare best by assisting the companies they invest in rather than by squeezing all they can get from them and thereby killing the incentive of the entrepreneurs they are backing.

\section{The small business investment company pro- gramme}

The small business investment company is well defined in a document produced by the National Association of Small Business Investment Companies in Washington.

A small business investment company is a privately organized, privately capitalized and privately managed source of venture capital for new and growing independant businesses. S.B.I.C.'s are licenced by the small business administration to comply with broad investment criteria established by the Small Business Investment Act of 1958 and subsequent S.B.A. regulations. In return for providing equity capital, long-term loans and management assistance exclusively to new and small businesses, S.B.I.C.'s are permitted to borrow funds from the Federal Government at an interest rate slightly above the cost of money to the federal treasury.

In addition to the S.B.I.C.'s there are the minority enterprise small businesses investment companies. These M.E.S.B.I.C.'s utilize the S.B.I.C. format to help socially or economically disadvantaged entrepreneurs. Today there are about 300 small business investment companies and 100 minority enterprise small business investment companies with total assets of about 1,5 billion U.S. Dollars.

To understand the significance of the small business investment programme one must be aware of the role of the small business in the American society. It is a nation of small businesses. I have already outlined some statistics at the beginning of this paper, but in addition to those, it is of interest to note that $97 \%$ of all unincorporated and incorporated businesses in the U.S.A. are independant. They generate $53 \%$ of all business receipts $(3,3$ trillion U.S. Dollars - 1978), and account for $43 \%$ of total gross national product. Small firms are also the greatest job creators as our earlier statistics illustrate. In addition to this the Department of Labour Statistics indicates that of the nine million new jobs created between 1969 and 1976, not one new job was in the largest 1000 corporations in the country. Six million of these jobs were created by small business and the remaining three million were in various levels of government (let us hope that our government departments don't grow at the rate of $331 / 3 \%$ of all new jobs created). In addition to this, small businesses are innovators. Economic progress depends upon innovation and over half of all inventions and innovations introduced into the American industry since World War II originated in small companies. A national science foundation study of the period between 1953 and 1973 concluded that small firms produced four times as many innovations per research and development dollar as medium sized firms and 24 times as many as the largest firms.

\section{Capital assistance}

The venture capital industry in the U.S.A. has grown and developed in response to the serious need for capital assistance to small firms. Venture capitalists generally seek small firms with better than average growth potential and provide long term loans, equity financing and substantial management assistance. They take a minority ownership position in the company and hope to be rewarded for their risks with capital gains.

With all this comparison in the U.S.A. small business programme, how successful has it been?

In its 21 year history the programme has been extremely successful providing over 3 billion U.S. Dollars to 40000 small companies. The National Association of Small Business Investment Companies used Arthur D. Little Inc. to conduct a survey of the economic progress of the companies. The data from various questionnaires were processed by the accounting firm of Deloitte, Haskins and Sells. The result of the study was truly impressive. According to key economic impact measures, 
S.B.I.C.-financed companies out-performed other small businesses by a factor of more than 10 to one. In the area of employment the figure showed that a permanent job has been created for each 4000 U.S. Dollars of a small business investment company investment (in contrast to 25000 U.S. Dollars that the government must spend annually to create and maintain a single job). The Federal government has profited from the increased tax revenues generated by small business investment company portfolio companies, which are from $150 \%$ to nearly $400 \%$ as great as those paid by all other small firms. Ninety-one percent of the growth of these companies has been the result of internal growth, rather than merger and acquisitions. In addition to the benefits directly attributable to small business investment company money, S.B.I.C. financing in many cases has enabled the small firm to qualify for additional senior debt such as bank lending.

\section{Tremendous benefits}

This whole programme, of course, is a partnership between public and private sectors which has proved extremely successful. Since 1958 the government has lost less than 30 million U.S. Dollars in the programme - an average of 1,5 million dollars per year. Together with administration costs the total programme costs the American taxpayers approximately 2,5 million dollars each year. This is well offset by the tremendous benefits which accrue to the economy as a result of small business activity. In 1979 alone more than 1670 small concerns received 280 million U.S. Dollars from the small business investment companies and the numbers are growing each year.

The programme can be improved but I do not intend to dwell on that in this paper as this in itself is the subject of yet another presentation. In any event I think we should at the end of this be concentrating on where we see venture capital playing a role in the South African context. In addition to some of the statistics I have given you on the availability of venture capital sources, there are almost three thousand other sources of venture capital outside the government programme. The strata and interest varies from high technology to ordinary trading companies.

As an example, Citicorp Venture Capital's present activities encompass a broad range of risk levels and business situations. Their principal objective in venture capital investments is the generation of long-term capital gain.

For the more mature companies they also provide longterm debt with a very small equity feature. This type of financing is often a less dilutive source of long-term capital than a straight equity financing and is typically used to provide growth capital or to refinance existing obligations on a longer term basis.

Through all this the size of the venture capital industry in the U.S.A. can be explained by a number of reasons:

- There are many interesting investment opportunities.

- The fiscal framework is conducive to making high risk investments in small firms.

- It is easier in the U.S.A. than in Europe, for example,to realize a venture capital investment because there is an active capital market for new issues.

- The U.S.A. government is willing to lend accredited investment company S.B.I.C.'s, three dollars for every dollar of their capital (about half the S.B.I.C.'s, those owned by banks and industrial corporations, are active venture capital investors, the others make secured loans or are involved in real estate transactions).

Yet venture capital is not the only reason that explains why the small and medium size business sector is so dynamic in the U.S.A.; other reasons have also contributed:

- A large domestic market.

- The appropriate fiscal framework.

- A society that encourages entrepreneurial initiative.

- The availability to small firms of Government Research and Development funds.

\section{Venture capital in Europe and the U.K.}

By contrast to the U.S.A. the European venture capital is extremely small. There are fewer than 30 institutional venture capitalists active in Europe that invest approximately 50 to 80 million U.S. Dollars each year. These venture capitalists tend for the moment to be more active in France than the U.K. although even at this stage of that industry's early development, venture capital investments are quite diversified both geographically and industrially.

In Europe to a greater or lesser extent the absence of the above factors boosting dynamic venture capital in the U.S.A., can explain both the small size of the venture capital industry and the predicament of stagnating small firms. The venture capitalists that were active in the late 1960 s and early 1970s are not necessarily those that are now active. In fact less than half are. The reason this change occurred was because most of the financial institutions that decided to dabble in venture capital chose the wrong moment to do so, and were ill-equipped to handle the problems that inevitably arose with the outbreak of the worst recession Europe has seen since the 1930s.

I might comment here, of course, that this situation is also very similar to that which arose in South Africa during the ' 60 s and '70s when certain large institutions also dabbled in venture capital and burnt their fingers. This resulted in their withdrawal from the venture capital market and to the best of my knowledge there is no major institution except as outlined later on, that is involved in venture capital per se in South Africa. The fact that the appropriate framework does not exist in Europe or for that matter in South Africa, that many ill-conceived venture capitalists in Europe could not survive and again could not survive in South Africa, should not be construed as omens of an impending death sentence upon the venture capital industry. The reverse in fact may be true. A national venture capital industry is emerging in continental Europe (it has existed for many years in the U.K.) and certain governments appear to be far more willing to establish the necessary framework for it to survive and to play an active role in helping channel long term funds into the small and medium size business sector. 
The current estimate of venture capital involvement in Europe is that some 120 million U.S. Dollars are now being invested annually.

\section{Income distribution}

There is little doubt that during the next few years and probably the rest of the century, changes in the energy market and persisting trends in the world's food/population balance will affect the international distribution of income and as a result increase socio-political tension world-wide. During this era of ever increasing tension and uncertainty, Europe's continuing importance as a regional industrial force will depend on its ability to vitalize its research and development capability, and thus improve productivity by increasing the pace of technological innovation. In attempting to set up a South African venture capital industry, our policy makers should not forget that even though the small and medium size business sector accounts for a small proportion of expenditure on research and development, it is an important source of innovation and a seedbed from which eventually new large companies emerge (this is particularly the case in Europe, for example where multi-national corporations such as Philips and Siemens were only small companies not so long ago).

I would also like to touch on the Institute of Directors Scheme (IOD) in the U.K. I am privileged to have read a copy of their paper $\mathrm{C} / 81 / 2$, I find this paper an excellent innovation for venture capital in the U.K. I would suggest that in many respects, it warrants serious consideration for the development on a similar line of the venture capital industry in Southern Africa.

\section{U.K. scheme - IOD}

The Institute in the U.K. distinguishes two elements to promote the fulfillment of the need for risk funding. I quote: 'The Institute is committed to the stimulation and growth of businesses and believes that the marriage of entrepreneurs and entrepreneurial investors is an unsatisfied need ... in particular it is also hoped that the lead given by the Institute will act as a catalyst for other organizations to follow our lead.'

In their research the Institute in London has in fact proved that in the banking system, although 'eloquent in proclaiming' that it is providing all the risk capital, there is still a major gap.

The first leg of the Institute's proposal is a venture fund scheme and it is interesting to note that apart from redeemable participating preference shares, the benefits accruing to the investee company are:

- There will be no requirement for a seat on the Board (But equally common sense monitoring will take place. The appointment by the company of non-executive or part time directors will be recommended).

- The company will not be penalized if profits are low.

- The company will have the ability to repay the preference shares if the profits are high.

The fund would have an average investment of approximately $£ 40000$. It is also interesting to note that the philosophy behind the entire scheme is that no security or guarantee is required which then leads to the ability of the investee company to have increased bank buying. There are certain restrictions in terms of borrowing powers by the company which would obviously have to be monitored by the fund.

The fund enables investors to spread their risk over a wide portfolio and, therefore, they have a substantially reduced risk. There are also various government incentives again which enable the investor to have certain tax benefits. The benefits of the fund as outlined by the Institute are as follows:

- Provision of capital without loss of ownership and control to the present owners of the enterprise.

- Provision for the investee receiving capital to withdraw from that investment at his option.

- To provide capital without inhibiting and if anything increasing the ability of the recipient company to use bank loans for expanding working capital requirements.

- To avoid the owners having to pledge personal assets as security.

- To enable private individuals investing in new enterprise to spread their risk in doing so.

- To enable entrepreneurial investors to obtain the full benefits of the tax concessions granted in the 1980 budget (subject to treasury approval).

- To enable entrepreneurs to replace overdraft facilities with a heavy interest burden with core capital.

- To increase the scale of venture capital investment and of new enterprise.

- To allow those investing in new enterprise to realize their investment in the market, thus providing greater liquidity than at present.

\section{The IOD Gazette}

The second leg of the proposal and scheme arranged by the Institute of Directors in London is the Gazette, which is termed a link between entrepreneurs and entrepreneurial investors. The benefits of the Gazette are as follows:

- 'To enable entrepreneurial investors to obtain the full benefit of the tax concessions granted in the 1980 budget.

- To provide a means to replace overdraft facilities with a heavy interest burden with core capital.

- To introduce the flexibility that individual investors can bring to financing new enterprise.

- To increase the scale of venture capital investment.

- To bring practical help and advice to entrepreneurs from professional businessmen associated with their investment.'

The Gazette, as I understand it, would be a magazine published bi-monthly to introduce direct investment from the investor to the entrepreneur.

A totally exciting concept which I believe certainly warrants a great deal of study and perhaps formation of such a venture in this country is long overdue. The two elements of the scheme are highly imaginative and present a new approach to venture funding and stimulation of new enterprise. Hopefully briefly then we have painted a picture of what exists elsewhere. How does this help us in the South African context? 


\section{Financing South African entrepreneurs}

Firstly let us have a quick glance at what the South African financial structure looks like. In 1975 the Standard Bank of South Africa Limited produced a very useful set of essays on the South African financial structure which was edited by Messrs Hammersma and Czypionka. Our financial structure commencing with our own South African Reserve Bank, is similar to that of most other countries in the western world. Then we have commercial banking, merchant banking, the land and agricultural bank of South Africa, building societies, discount houses and a money market; we have unit trusts, hire purchase savings and general banks; we have leasing, the stock exchange, and short and long term insurers; we have private pension and provident funds and we only now have our own venture capital institution in the form of the Small Business Development Corporation Limited.

Have we to date stimulated venture capital? As I mentioned earlier we have had in fact a number of institutions in this country dabbling, and very much so, in venture capital. They burnt their fingers and I doubt that they will readily set up their own venture capital departments again. To my mind the main problem they faced is a typical one of lack of proper monitoring of the situation and controlling the investment portfolio. This by no means advocates interference but does mean that any venture capitalist must pay attention to many factors of venture capital, particularly the screening process, proper structuring of the investment, monitoring the postinvestment phase and monitoring in terms of the postinvestment phase as against management interference or assistance. I personally have very little sympathy for the failure to date of the venture capital industry in South Africa because I do believe that the institutions adopted a typical bureaucratic approach in the hope that they would have had a greater return on investment. I personally think that what they failed to realize at the time was the degree of risk involved in a high profit situation. I believe eventually this becomes a very balanced affair, a very delicate balance between the provision of capital, the controlling thereof, and the maintenance of creativity and innovation in the entrepreneur.

In addition to the small business development corporation, we of course had for many years our industrial development corporation. The I.D.C. has not really fulfilled a true venture capital niche in the South African context. I have also noted in the past week or so that Barclays Bank have announced the formation of a new capital package. This package regrettably is aimed at companies with turnovers in excess of R10 million and with product unit costs between R50 000 and R200 000 . This is obviously aimed at the capital goods manufacturers who I believe in most cases are able to obtain finance from traditional sources. I have no doubt that the Barclays scheme is aimed at giving further leverage to these companies so that they will be able to utilize the traditional finance sources by the utilization of their package.

I am indebted to Finansbank for certain statistics and information they have produced fairly recently in their consideration and establishment of a venture capital division within their bank.
However, I am still extremely critical of the approach towards venture capital in this country and I look forward certainly with great interest to the parameters that may be set by the Small Business Development Corporation when they eventually finalize their approach, philosophy and area of investment.

\section{Basic principles of lending}

I think we all know, and have seen in South Africa, how sources of finance are very much on the traditional road. I use that of course in the context of the institutions. We often joke about commercial banks lending us $R 100$ provided we put $R 500$ down on a fixed deposit. It may seem a joke but this actually does exist. How many times have many of us been to bankers and asked for facilities and been told 'Well, what security have you got?' Even if you can produce an operating company, you find it difficult to obtain facilities from commercial banks if no balance sheets are available. This means that very often you may have to wait a year before you are in a position to seek a facility. This could seriously deter the promotion of entrepreneurship.

There are three basic principles behind all bank lending.

$$
\begin{aligned}
& \text { - Safety. } \\
& \text { - Suitability. } \\
& \text { - Profitability. }
\end{aligned}
$$

Apart from this I am not going to embark upon an exhaustive analysis on the basic principles of bank lending. It is well established that the true function of a commercial bank as a lender in this country today is normally to afford only short term accommodation when required for approved purposes. This may appear to be a sweeping assertion and it must be admitted that exceptions have occasionally had to be made for special reasons, but in general it is not the function of the bank to furnish funds needed for long periods or to compete with other specialized houses in granting of long-term accommodation. To quote L.C. Mather in his book, The Lending Banker, 'it would be unwise today to share with an inexperienced borrower the obvious risks entailed in tapping or exploring a new market for business. The past record of any borrower is an invaluable guide. Why lend to enable any customer to embark upon a fresh project quite remote from his previous business training or experience'.

Of course, bankers are able to quote countless examples from practice where it has been unwise to advance funds for new projects or new ideas. However, again I believe that this is because of the institutional philosophy and concept and not necessarily because of circumstances.

\section{Franchises}

In the January 1981 edition of 'Business South Africa', there is an article referring to 'the small entrepreneur's last chance'. This article covers the question of franchise which they maintain is a partnership - difficult though it is, it could be a winner in South Africa. I personally am not a great believer in franchise operations, even though certain aspects are indeed useful. As a general rule I believe that the franchise operation is nothing more than 
a rip-off and a method by which a man with one idea is able to capitalize on a generally mediocre return for the franchise fee. Franchising in South Africa is not based on established business in South Africa but more on established business elsewhere, particularly in the U.S.A. In many cases these franchises are not household names in this country but only become so once the franchisor has in fact created innumerable franchises throughout the country. Therefore I believe that the franchise system is not producing the quid pro quo. To quote from the article: 'It could be the way in which white entrepreneurs dispense their "know-how" and financial leverage to the black trader, not only in South Africa and the homelands, but also in other parts of Southern Africa'. To me there are some dangers in taking this route to promote free enterprise and encourage entrepreneurs. Hopefully, our Small Business Development Corporation will provide new alternatives to fill the gap which has long existed in this country.

\section{Entrepreneurial function}

The essential function of the entrepreneur is to recognize the commercial potential of a product or service; to design consistent operating policies in marketing, market research, production, finance, product development and the organizational structure and systems for that product or service; and then to supervise the changes required in the strategy through the various stages of company growth. The ability to conceptualize, to design and to supervise are all needed by the successful small business manager. Smaller business firms lack almost by definition the financial resources and the market size that provide competitive advantage to the larger corporations; the small business manager must design operating policies in all of these functional areas and through all of the stages of growth that adjust to these inherent deficiences. The small business management requires imagination, perception and innovation to survive and to grow; it is very different from the management of larger companies that can utilize capital and market size to maximize a return on investment.

\section{Characteristics of the entrepreneur}

To quote John L. Hines, President of Continental Hllinois Venture Corporation: 'It is difficult to enumerate in order of priority the most important characteristics of the entrepreneur. There are two reasons why this task is formidable.

- There are several characteristics which seem both inherent and essential to all successful entrepreneurs, a deficiency in any of these essentials usually portends failure.

- Most venture capitalists tend to be quite subjective in weighing other characteristics which may not be so universal or prominent.'

Every venture capitalist agrees that successful entrepreneurs must be honest, intelligent, skillful and well educated in their chosen fields (not necessarily as a result of formal education). There have been relatively few, if any, long lived successful venture companies led by people deficient in any one of these four essential qualities. Knowledgeable investors would decline par- ticipation opportunities in such ventures.

John $\mathrm{L}$. Hines quotes nine traits in all venture candidates with no particular order or priority.

- Energy level

- Ego

- Courage

- Enthusiasm

- Desire to make money

- Creativity

- Resourcefulness

- Tenacity

- Leadership qualities.

He goes on to say that 'unless an entrepreneur has an abundance of all these qualities, one might pause and be more careful when considering becoming his or her partner. The weighing of each of these characteristics must by necessity be purely subjective'.

\section{Venture approach}

So where do we go from here? From the institutional standpoint not only is venture capital an area where the highest potential returns are offered, it is also where social pressures make it increasingly appropriate to commit more funds. While venture pools or syndicates for the near term seem most appropriate, over the longer term perhaps they will be supplemented by newly conceived financial intermediaries.

New investment approaches, more realistic appraisal of values, and professionals who are more widely trained and versatile are essential to set small business in this country on a sounder footing. The government appears to have a rising awareness of the need for capital investment and the mobilization of small business activists. A particular aim in this country, I would suggest, is to promote the advance of technology during the next decade. These measures would lead to substantially increased capital requirements and hopefully commitments in the area by both the public and institutions and should ultimately lead to a more viable market and higher valuations for venture sponsored companies.

The institutions must be made aware that although a small business operating in a steady state may be able to get by, even possibly do well with no written planning and within informal monitoring procedures only, the company aiming at rapid growth has much better odds of success in the eyes of professional evaluators such as venture capitalists if it operates from a well prepared written plan. However, this should not lead to a bureaucratic system of preparing plans. In any event it is fact and it has been observed that companies that do not follow their plans often do better than those that do, but both do better on growth projectories if they have formal plans. The advantages of plans are that they force management to think through in detail what must happen in order to achieve success and they provide lead time for acquisition of resources, that cannot be obtained on the spur of the moment, that they give members of the company a common understanding of what is to be done, they make people in the company think harder about what is to be done and thereby raise the odds of getting better ideas on how to accomplish it. And once plans are prepared they allow 
people to concentrate on doing the job instead of constantly having to worry about what the job should be. At the same time willingness to depart from plans, allows flexibility to take advantage of new ideas and unforeseen opportunities. Flexibility is often cited as a major advantage unique to small companies.

I believe that institutions and investors must overcome their staid phobias, an example of which is the consideration of whether or not an entrepreneur is able to do the job. The question should focus more on whether he has selected a good team and can build a good team around him, rather than his track record. The attitude of investors in South Africa is 'what sort of track record has he?' before they will even contemplate an investment. If we are to sponsor and promote venture capital and entrepreneurs in South Africa we have to accept that seed capital or the investing in no track record is a prerequisite for the establishment of venture capital opportunities. I believe that the importance of the venture capital industry in Southern Africa will begin to become more apparent when institutional investors realize that they will have to use the screening and monitoring techniques developed by venture capitalists elsewhere and also in South Africa on a much wider scale in future to channel funds into the private sector without using the capital market system. The ability of all but the top tier corporations to raise the necessary long-term capital is now in doubt.

This does not mean that the Southern Africa venture capital industry now commencing its life is in itself unimportant. We have the start through the Small Business Development Corporation which boasts over R100 million in capital. At this stage it is not clear how long it will take to invest that money. In Europe for example over 100 million dollars will be invested in 1981: One third in new projects and the balance in existing ones.

\section{Venture evaluation}

While the South African scene may seem insignificant in quantum in global terms, in many cases it might prove to be the only source of capital for dynamic small Southern African companies. One of the main difficulties small and medium size businesses will continue to face is the means to finance their future growth. From the outset through all three phases of development, it will be essential for Southern African institutions and individuals to creatively and effectively use new techniques of financing to inject long-term capital into the small and medium business sector, otherwise the dynamism of this sector of the economy will erode slowly and inevitably the pace of innovation will suffer. Venture capital is a financing technique that can be used to revitalize the dynamic subsegments of the small and medium business sector.

I believe a venture capitalist needs to evaluate three basic factors, firstly the leader's determination and personal commitment as an independent businessman, secondly the team's management capability and thirdly the potential of the product process and service to be offered and whether this can be the core of an independent business.

Outside these parameters I believe it becomes a matter of detail and, if too finite, it leads to a bureaucratic approach which results in missed opportunities. Consider- ing seed or development capital as the philosophy for investment, the evolution of each company must be considered; it is possible to define the three stages most companies go through, despite their different evolutions:

- Start-up

- Implementation

- Development.

The start-up stage spans the period from earliest conception plus pre-incorporation to the time the product is successfully prototyped. During this period the company may secure one or two orders for its prototypes.

The implementation stage covers the period during which an order book is built up and a product undergoes successive modifications, simultaneous to being engineered for production; during this stage marketing is at an embryonic level and a company is usually operating at a loss. An additional round of financing to market a product is usually necessary.

Development stage spans the period from the time the company begins to market the standardized product to the moment it has established a niche in the market. During this stage sales are bound to expand at a very rapid pace and the company begins to earn profit. Further financing is usually required to attain foreseeable objectives.

\section{Conclusion}

The risk a venture capitalist takes clearly depends on the extent to which he is willing to finance companies in the start-up rather than the development stage. The time is not the only parameter. For example the risk a venture capitalist assumes, is clearly dependent on how competent the management of the future investee is.

How committed are our venture capitalists or institutions in South Africa going to be to financing seed capital for the start-up stage? These are normally grass root situations and most venture capitalists claim that in theory they will consider seed capital projects, but admit that it is highly unlikely that they will invest in them. The reason why only some venture capitalists will invest in grass root situations is not only that the risk is high, but also that it is rarely possible to make a large enough equity related minority investment. This might appear to be a paradox although it is not. The profit a venture capitalist seeks, must ensure a return commensurate to the risk after having financially accounted for the time a venture capitalist has spent nursing an investment to fruition. Because of the various complications the venture capitalists who do invest in grass root situations are those that are willing to accept the higher risk and that are willing to devote time to the project in relation to the size of their commitment.

All venture capitalists are interested in projects that are at the implementation and development stages.

My great hope is that the South African institutions will no longer remain curators of business but will become innovators and I personally look forward to seeing how Small Business Development Corporation through its own resources and through its own impetus to generate ef fective support systems for small business, will be the new star supporter of free enterprise, entrepreneurship and venture capital. 